\title{
Temporal Intermittent Rhythmic Delta Activity (TIRDA) in the Diagnosis of Complex Partial Epilepsy: Sensitivity, Specificity and Predictive Value
}

\author{
Jean Reiher, Michel Beaudry and Charles P. Leduc
}

\begin{abstract}
Temporal interictal rhythmic delta activity or TIRDA was found in 45 of the 127 recordings of patients with complex partial epilepsy (CPE) referred for both awake and sleep EEG. TIRDA was more abundant during drowsiness and light sleep; it occurred more characteristically as trains of 50-100 $\mu \mathrm{v}$ sinusoidal or saw-toothed $1-4 \mathrm{~Hz}$ activity, recorded predominantly from anterior temporal regions. When occurring bilaterally and independently, TIRDA varied from side to side. TIRDA is often found in association with anterior temporal spikes or sharp waves (TS) particularly during sleep, as observed in 43 out of 45 EEGs. TIRDA can nevertheless occur as an isolated abnormality, as noted in two sleep and 12 awake study recordings. Because of its high specificity and positive predictive value over a large range of prevalence, TIRDA should be singled out as an accurate interictal indicator of CPE. In patients with isolated TIRDA, the cost of prolonged EEG recording during sleep for the purpose of activating TS has to be weighed against the yield of eventually confirming the obvious.

RÉSUMÉ: TIRDA ou activité rythmique temporale inter-critique dans le diagnostic de l'épilepsie partielle complexe: sensibilité, spécificité et valeur prédictive Chez $35 \%$ des malades adressés pour investigation d'une épilepsie partielle complexe, l'électroencéphalogramme a révélé en temporal une activité delta rythmique inter-critique (TIRDA). Plus abondant durant somnolence et sommeil léger, le TIRDA se présente plus classiquement sous forme de train d'ondes de $\mathrm{I}$ à $4 \mathrm{~Hz}$, d'une amplitude allant de 50 à $100 \mu \mathrm{v}$. Lorsque bilatéral, le TIRDA survient de façon asynchrone et avec une morphologie distincte de chaque côté. Souvent associé à des pointes temporales antérieures (TS), le TIRDA peut se retrouver néanmoins de façon isolée. A cause de sa très grande spécificité et de sa valeur prédictive élevée pour un large spectre de prévalence, le TIRDA mérite d'être retenu comme un indicateur intercritique pathognomonique de l'épilepsie partielle complexe. Les inconvénients d'un enregistrement prolongé pendant le sommeil, à la recherche de la pointe temporale classique, méritent d'être souspesés lorsque le TIRDA représente la seule anomalie recueillie lors d'un électroencéphalogramme initial.
\end{abstract}

Can. J. Neurol. Sci. 1989; 16:398-40I

EEG recordings are most useful in the evaluation of patients with complex partial epilepsy (CPE). Even though they seldom record seizures, they often reveal significant interictal abnormalities. Anterior temporal spikes or sharp waves (TS) constitute the principal interictal pattern. ${ }^{1}$ Spikes located in a region outside the temporal area are much less common. 2,3

"Psychomotor variant type of seizure discharge", wicket spikes, small sharp spikes and 14 and $6-\mathrm{Hz}$ positive spikes are also recorded over the temporal regions, but they are of no clear relevance in the diagnosis of CPE.4-11

Temporal intermittent rhythmic delta activity, or TIRDA, is an abnormality which involves chiefly the temporal regions.
Despite its location, TIRDA has not been singled out to date as a possible marker for CPE.

The purpose of this study is threefold: to define for the first time the electroencephalographic characteristics of TIRDA, to assess TIRDA's validity as a possible accurate interictal indicator of CPE, and to evaluate the positive predictive value of TIRDA as an interictal marker of CPE.

\section{Material AND Methods}

The study material consisted of 127 recordings from 115 adult patients with a clinical diagnosis of CPE seen consecutive-

From the Department of Neurology (J.R., M.B.), and the Department of Community Health Sciences (C.P.L.), University of Sherbrooke, School of Medicine, Sherbrooke, Quebec

Received January 5, 1989. Accepted in final form June 12, 1989

Presented at the 1987 Annual Meeting of the American Electroencephalographic Society, September 17-19, 1987, St-Louis, Missouri

Reprint requests to: Dr. J. Reiher, Department of Neurology, University of Sherbrooke, 3001, 12th Avenue North, Sherbrooke, Quebec, Canada J1H 
ly between 1984 and 1986. All patients were examined by neurologists. The comparison group consisted of 115 recordings in 115 age-matched adult patients with a clinical diagnosis other than CPE seen consecutively over the same period by the same neurologists. Availability of EEG recordings during both wakefulness and sleep was mandatory for inclusion in either group.

Patients assigned to the diseased group included those with a history of stereotyped attacks of impaired consciousness and automatisms, with or without ictal or interictal abnormalities in the EEG; those with a clinical diagnosis of temporal lobe or psychomotor seizures, with or without recorded TS; and those with a history of generalized nocturnal or diurnal seizures, or seizures unheralded by a characteristic aura, with recorded TS.

Taking into account the methodological vulnerability of patient selection based primarily on clinical judgment, a subgroup of patients is defined where the diagnosis of CPE is based on the gold standard of the presence of TS in the recordings.

Patients assigned to the control group were referred for seizures other than CPE and for various conditions such as syncope, drop attacks, transient global amnesia and hyperventilation syndrome.

Finally, the presence or absence of TIRDA in the EEG had no bearing on the clinician's classification of the seizures, nor on the assignment of patients to either group. TIRDA, unlike TS, had yet to be identified as a distinctive pattern in our laboratory, and had never been reported as a "specific" interictal abnormality to the attending neurologist.

Sensitivity (Sn), specificity (Sp) and positive predictive value $(\mathrm{PV}+)$ were calculated according to the usual formulae. ${ }^{11}$ Since the predictive value is a function of prevalence $(\mathrm{P})$ as well as of sensitivity and specificity, the proportion of patients with CPE in the adult population referred to our laboratory for both wake and sleep recordings was also calculated.

The sensitivity $(\mathrm{Sn})$ of a diagnostic test, or in this case of an EEG pattern, refers to its ability to identify patients with the disease. It is the ratio of the true positive test (TP) to all of the patients with the disease, ie. those that tested positively and those that falsely tested negatively (FN):

$$
\mathrm{Sn}=\mathrm{TP} /(\mathrm{TP}+\mathrm{FN})
$$

The specificity (Sp) of a test refers to its ability to detect the non-diseased patients. It is the ratio of the true negative test (TN) to all of the non-diseased patients, i.e. those testing negatively and those falsely testing positive (FP):

$$
\mathrm{Sp}=\mathrm{TN} /(\mathrm{FP}+\mathrm{TN})
$$

The predictive value of a positive value test $(\mathrm{PV}+)$ refers to the probability that an individual with a positive test will actually have the disease in question. It varies with the prevalence of the disease $(\mathrm{P})$ :

$$
\mathrm{PV}+=(\mathrm{Sn})(\mathrm{P}) /[(\mathrm{Sn})(\mathrm{P})+(1-\mathrm{P})(1-\mathrm{Sp})]
$$

\section{RESULTS}

TIRDA and TS occurred more frequently during sleep than during wakefulness; they were respectively found in $45(35 \%)$ and in $77(60 \%)$ out of the 127 sleep EEGs of patients clinically diagnosed with CPE (Table 1). Three patients with CPE had extratemporal interictal spikes (frontal in two, occipital in one), but no TIRDA. In the control group, no TS nor TIRDA were found in any patient.

TIRDA occurred as short bursts of a few seconds duration. They were more easily identified during drowsiness and light sleep where they characteristically occurred as trains of $10 \mathrm{sec}-$ onds or more of repetitive, rhythmic, saw-toothed or sinusoidal $1-4 \mathrm{~Hz}$ activity of $50-100 \mu v$ in amplitude (Figures 1 and 2). TIRDA was recorded predominantly from anterior temporal regions and often spread considerably to the ipsilateral ear, midtemporal and fronto-polar areas. TIRDA's morphology was rather stereotyped in a given patient, although it varied from patient to patient. When occurring bilaterally and independently, TIRDA's appearance often differed from side to side.

TIRDA was often found in association with TS (Table 1), in 22 out of 34 awake recordings and in 43 out of 45 sleep recordings. A unilateral TIRDA invariably occurred with an ipsilateral spike focus during wakefulness, and almost always, with one single exception, during sleep. Bilaterally independent TIRDAs are associated with bilaterally independent TS in 7 out of 12 awake recordings, and in 14 out of 16 sleep recordings.

TIRDA was found in recordings (Table 1) as an isolated abnormality without TS, in 12/34 tracings during wakefulness and 2/45 during sleep. More prolonged recording during sleep in five patients revealed TS. TS can also be the only interictal abnormality, as in 23 awake and 34 sleep recordings (Table 1).

Seizures were recorded in 13 patients. The ictal discharges in all 13 patients were different from those of the interictal

Table 1: Distribution of TIRDA and TS in Recordings of Patients with Clinically Diagnosed CPE and in Control Recordings, During Wakefulness and Sleep

\begin{tabular}{lrcrr}
\hline & \multicolumn{2}{c}{ Awake } & \multicolumn{2}{c}{ Asleep } \\
Recorded abnormalities & CPE & Control & CPE & Control \\
\hline Both TIRDA and TS & 22 & 0 & 43 & 0 \\
TIRDA alone & 12 & 0 & 2 & 0 \\
TS alone & 23 & 0 & 34 & 0 \\
No TIRDA nor TS & 70 & 115 & 48 & 115 \\
Total & 127 & 115 & 127 & 115 \\
\hline
\end{tabular}

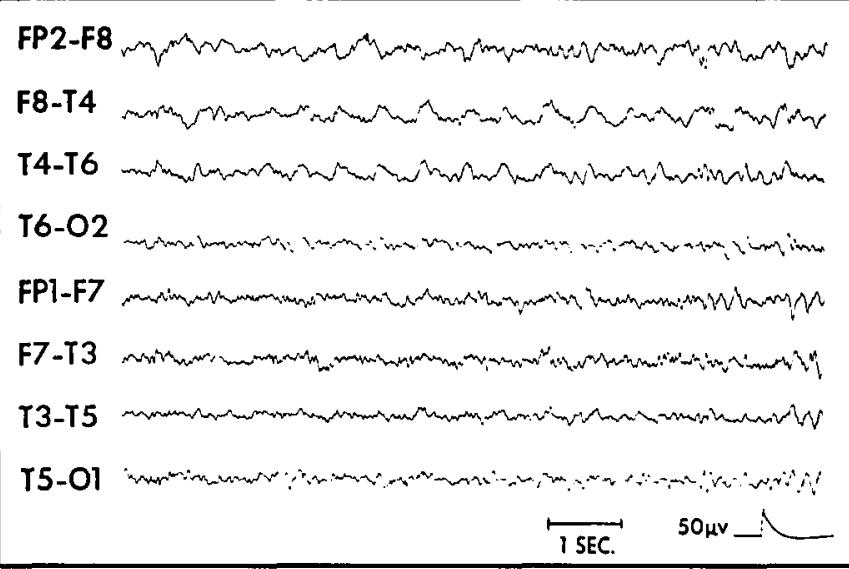

Figure 1 - Train of sustained, repetitive TIRDA with phase reversal at $F_{8}$. 
TIRDA. Furthermore, no clinical sign was ever observed in association with even the most prolonged trains of TIRDA.

Data on sensitivity, specificity, positive predictive values and prevalence are given in Table III: specificity and positive predictive values for TIRDA are extremely high.

According to Bayes' theorem, ${ }^{11}$ the predictive value of a positive test $(\mathrm{PV}+)$ of known sensitivity and specificity varies with changing prevalence. Whenever specificity is $100 \%, \mathrm{PV}+$ remains unchanged $(100 \%)$ regardless of prevalence. There is however ample evidence in clinical medicine that in larger series false positives are bound to occur. Their impact on PV+ is particularly important in low prevalence situations.

Therefore, to conform with clinical reality, calculations were made using an arbitrarily chosen specificity value of $99.9 \%$

Table 2: Sensitivity, Specificity and Predictive Value of TIRDA in Recordings of Patients with Clinically Diagnosed CPE and in Control Recordings, During Wakefulness and Sleep

\begin{tabular}{|c|c|c|c|c|}
\hline & \multicolumn{2}{|c|}{$\begin{array}{c}\text { Awake } \\
\text { Recordings }\end{array}$} & \multicolumn{2}{|c|}{$\begin{array}{c}\text { Asleep } \\
\text { Recordings }\end{array}$} \\
\hline & $\mathrm{CPE}$ & Control & CPE & Control \\
\hline TIRDA present & 34 & 0 & 45 & 0 \\
\hline TIRDA absent & 93 & 115 & 82 & 115 \\
\hline Total & 127 & 115 & 127 & 115 \\
\hline Sn: & \multicolumn{2}{|c|}{$26.8 \%$} & \multicolumn{2}{|c|}{$35.4 \%$} \\
\hline Sp: & \multicolumn{2}{|c|}{$100 \%$} & \multicolumn{2}{|c|}{$100 \%$} \\
\hline PV+: & \multicolumn{2}{|c|}{$99.5 \% *$} & \multicolumn{2}{|c|}{$99.6 \% *$} \\
\hline $\begin{array}{l}\text { Prevalence of clinically } \\
\text { diagnosed CPE: }\end{array}$ & \multicolumn{4}{|c|}{$40.5 \%$} \\
\hline
\end{tabular}

*Calculated with a specificity of $99.9 \%$

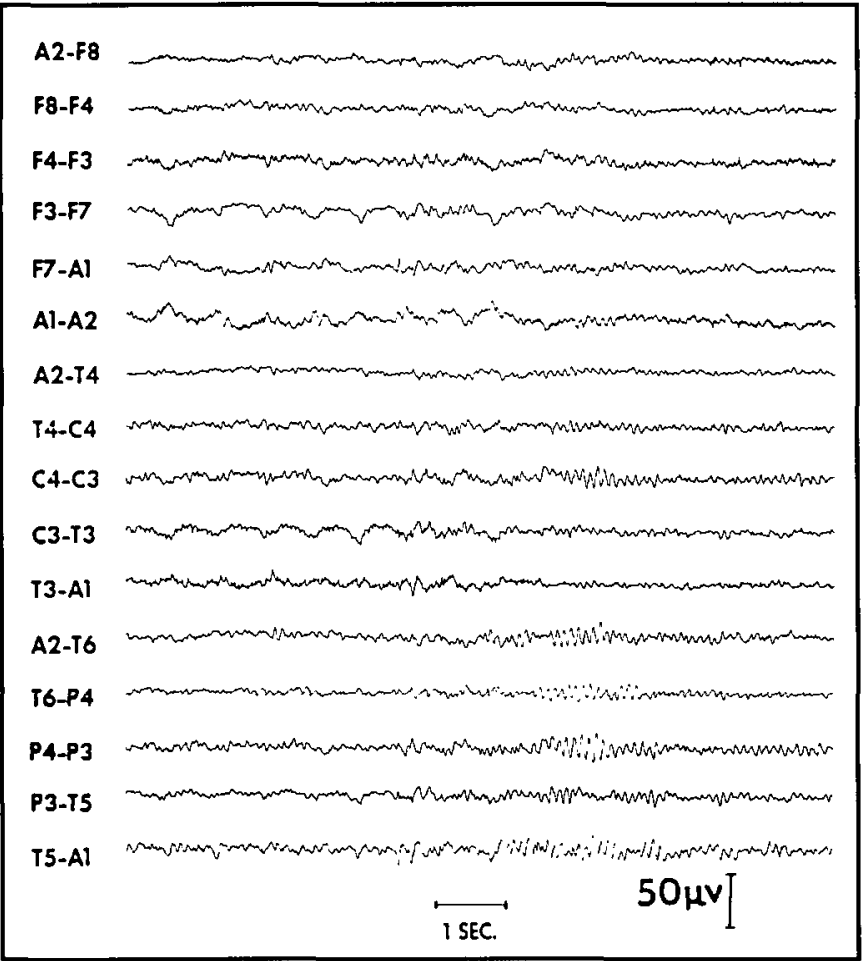

Figure 2 - Train of sinusoidal TIRDA seen simultaneously, unlike a pulse artefact, in several derivations $\left(F_{3}-F_{7}, F_{7}-A_{l}, A_{1}-A_{2}, C_{3}-T_{3}\right.$, $\left.T_{3}-A_{1}, P_{3}-T_{5}\right)$.
(Table 2). With a prevalence for CPE of $40.4 \%$ such as found in our laboratory, a specificity value of $99.9 \%$ does not significantly alter the PV+. Obviously, PV+ decreases with decreasing prevalence rates (Figure 3). Even with a prevalence for $\mathrm{CPE}$ as low as $6.6 \%$, a much lower figure than would be expected in any general laboratory which deals with epileptic patients referred by neurologists, the PV+ of TIRDA during wakefulness or sleep would still remain very high (95\%).

\section{Discussion}

TIRDA is a relatively common pattern (Table 1). It can occur as an isolated abnormality, or more frequently in association with TS.

Both TIRDA and TS are predominantly located in the anterior temporal region. Both spread considerably to the ear, to fronto-polar and to mid-temporal regions. The lateral concordance of both patterns is also striking. TIRDA generally occurs ipsilaterally in patients with a unilateral TS focus, and bilaterally and independently in patients with bilateral independent TS foci. Exceptions to such a concordance between TIRDA and TS can probably be best explained by insufficient EEG sampling during sleep. Indeed in the 12 patients with TIRDA who did not have TS in wakefulness, 10 of them showed concordant spike foci after two hours of additional recording during sleep.

TIRDA is more sustained, repetitive and rhythmic than the sporadic temporal delta waves found in the aged.14.15 TIRDA does not have the EEG characteristics of a larval seizure. ${ }^{12}$ Like repetitive interictal TS, TIRDA is not associated with the clinical accompaniments of a seizure. ${ }^{3}$ It is true that at some point during the course of a recorded seizure, sustained repetitive delta activity resembling TIRDA can occur; such discharges can easily be differentiated from the monomorphic interictal TIRDA, since they are preceded and followed by equally sustained discharges which change in morphology, amplitude, repetition rate and distribution.

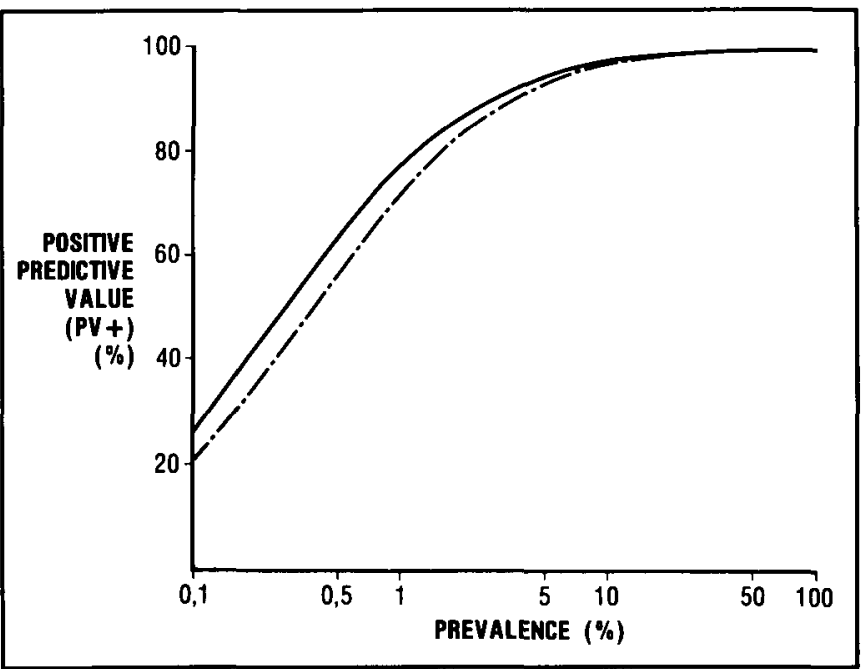

Figure $3-$ Effect of changing prevalence of clinically diagnosed $C P E$ on positive predictive value $(P V+)$ of TIRDA during wakefulness (._-_-___. ) and sleep ( ). 
It has been postulated that "based on evidence from depth electrography, localized slow-wave abnormality in scalp EEGs, especially if it occurs rhythmically, may represent an epileptogenic discharge situated deeply within the brain...". ${ }^{13}$ Could it be possible that TIRDA represents recordings on the scalp of repetitive after-slow waves stemming from equally repetitive desynchronized spikes in the depth? Intensive monitoring of TIRDA in CPE patients with simultaneous depth and surface recordings may well provide a more definitive answer.

The validity of TIRDA needs to be assessed in reference to a gold standard for CPE. Mandatory recording of ictal events by EEG and video monitoring as a prerequisite for diagnosis would be an unrealistic standard in every-day neurological practice. Seizures are seldom recorded in laboratories other than those specialized for intensive monitoring of surgical candidates with frequent, uncontrolled seizures. Exclusion of patients from the diseased group on the grounds that ictal abnormalities and/or interictal abnormalities are lacking in available recordings would also be unrealistic. A significant number of patients with bona fide CPE have normal EEGs even after examination during sleep. ${ }^{2,13}$ In this study, clinical diagnosis prevailed for allocation of patients in the diseased and non-diseased groups, in conformity with the axiomatic teaching that the diagnosis of epilepsy rests foremost on sound clinical observation.

Had the presence of TS during sleep been required as a gold standard for a diagnosis of CPE more definitive than one defined purely on the basis of clinical history, data regarding TIRDA's sensitivity, specificity and positive predictive value would then read as in Table 3. Specificity $(98.7 \%)$ and PV+ (93.3\%) of TIRDA in our setting would remain high even under those more stringent conditions of patient selection.

TS is not found in any patient of the control group. Its high specificity undoubtedly accounts for the unchallenged reputation it has deserved as the prototype of CPE interictal abnormal-

Table 3: Sensitivity, Specificity and Predictive Value of TIRDA During Sleep Using the Presence of TS as a Gold Standard for the Diagnosis of CPE.

\begin{tabular}{lcc}
\hline \hline & TS Present & Asleep \\
& TS Absent \\
\hline TIRDA present & 43 & 2 \\
TIRDA absent & 34 & 151 \\
Total & 77 & 153 \\
Sensitivity & & $: 55.8 \%$ \\
Specificity & $: 98.7 \%$ \\
PV+ & & $: 93.3 \%$ \\
Estimated prevalence of & \\
TS-documented CPE in our setting & $: 24.5 \%$ \\
\hline
\end{tabular}

ity. ${ }^{13}$ Why then single out TIRDA as another interictal marker for CPE? What does TIRDA's recognition add to patient evaluation? The positive predictive value of a diagnostic endeavor gives the frequency with which a positive test actually signifies disease. With a positive predictive value close to $100 \%$ over a large range of prevalence (Figure 3), TIRDA deserves to be regarded as a reliable interictal marker for CPE.

It is therefore reasonable to conclude that the presence of TIRDA, whether or not an isolated interictal abnormality, is as reliable as TS for the diagnosis of CPE. Finally, in patients with isolated TIRDA, the added cost of prolonged EEG recording during sleep for the purpose of activating TS has to be weighed against the yield of eventually confirming the obvious.

\section{REFERENCES}

1. Gibbs EL, Gibbs FA, Fuster B. Psychomotor epilepsy. Arch Neurol Psychiat 1948; 60: 331-339.

2. Gibbs FA, Gibbs EL. Atlas of Electroencephalography. Epilepsy 1952; Vol. 2, 2nd Ed. Addison-Wesley, Reading, Mass.

3. Gastaut H, Naquet R, Vigouroux R, et al. Elude électrographique chez l'homme et chez l'animal des décharges épileptiques dites "psychomotrices". Revue Neurologique (Paris) 1953; 88: 310354.

4. Gibbs FA, Gibbs CL, Gibbs EL. Psychomotor variant type of seizure discharge. Neurology 1963; 13: 991-998.

5. Reiher J, Lebel M. Wicket spikes: clinical correlates of a previously undescribed EEG pattern. Can J Neurol Sci 1977; 4: 39-47.

6. Reiher J, Klass DW. Two common EEG patterns of doubtful clinical significance. Med Clin North Am 1968; 52: 933-940.

7. Reiher J, Lebel M, Klass DW. Small sharp spikes (SSS): reassessment of electroencephalographic characteristics and clinical significance. Electroencephalogr Clin Neurophysiol 1977; 43: 775.

8. White JC, Langston JW, Pedley T. Benign epileptiform transients of sleep: clarification of the "small sharp spike" controversy. Neurology 1977; 27: 1061-1068.

9. Lombroso CT, Schwartz IH, Clark DM, et al. Cienoids in healthy youths. Neurology 1966; 16: 1152-1158.

10. Maulsby RL. EEG patterns of uncertain diagnostic significance. In: Klass DW, Daly DD, eds. Current Practice of Clinical Electroencephalography. New York, Raven Press, 1979; 411419.

11. Griner PF, Mayewski RJ, Mushilin AI, et al. Selection and interpretation of diagnostic tests and procedures: principles and application. Ann Intern Med 1981; 94: 553-600.

12. Gibbs FA, Gibbs EL, Lennox WG. Epilepsy: a paroxysmal cerebral dysrhythmia. Brain 1937; 60: 377-388.

13. Klass DW. Electroencephalographic manifestations of complex partial seizures. Chap 6. In: Penry, Daly, eds. Advances in Neurology. Vol. 11, Raven Press 1975; 113-140.

14. Obrist WD. The electroencephalogram of normal aged adults. Electroencephalogr Clin Neurophysiol 1954; 6: 235-244.

15. Reiher J, Klass DW. The significance of delta waves in the EEG of elderly patients. Electroenceph Clin Neurophysiol 1964; 17: 711. 